\title{
Rapid adaptive evolution to drought in a subset of plant traits in a large-scale climate change experiment
}

\author{
Johannes Metz ${ }^{1}$, Christian Lampei ${ }^{2}$, Laura Bäumler ${ }^{3}$, Herve Bocherens ${ }^{3}$, Hannes \\ Dittberner $^{4}$, Lorenz Henneberg ${ }^{3}$, Juliette de Meaux ${ }^{5}$, and Katja Tielbörger ${ }^{6}$ \\ ${ }^{1}$ Universität Hildesheim \\ ${ }^{2}$ University of Münster \\ ${ }^{3}$ University of Tübingen \\ ${ }^{4}$ University of Cologne \\ ${ }^{5}$ Universitat zu Koln Mathematisch-Naturwissenschaftliche Fakultat \\ ${ }^{6}$ University of Tuebingen, Institute of Botany
}

May 5, 2020

\begin{abstract}
Rapid evolution of traits and of plasticity may enable adaptation to climate change, yet solid experimental evidence under natural conditions is scarce. Here, we imposed rainfall manipulations $(+30 \%$, control, $-30 \%)$ for ten years on entire natural plant communities in two Eastern Mediterranean sites. Additional sites along a natural rainfall gradient and controlled selection analyses assessed whether potential responses were adaptive. In both sites, our annual target species Biscutella didyma consistently evolved earlier phenology and higher reproductive allocation in dry plots. This response was adaptive, as it aligned with theory, corresponding trait shifts along the natural rainfall gradient, and selection analyses under differential watering in the greenhouse. However, another seven candidate traits did not evolve, and there was little support for evolution of plasticity. Our results provide compelling evidence for rapid adaptive evolution under climate change; yet, they also call attention to potential constraints for full adaptation.
\end{abstract}

\section{INTRODUCTION}

Rapid adaptive evolution is considered a potential pathway for species to cope with ongoing climate change. Principles of rapid evolution have been studied abundantly by artificial selection under controlled conditions with short-lived, often single-cell organisms (reviewed in Barrett \& Schluter 2007; Hoffmann \& Sgró 2011). However, translating these findings to real life is difficult: multiple interacting factors may substantially impede rapid adaptive evolution under natural conditions, including e.g. environmental fluctuations, a multitude of biotic interactions, low genetic variation and trait heritability, genetic drift, or trade-offs between selected traits (Hoffmann \& Sgró 2011; Shaw \& Etterson 2012). Thus, there is an urgent need for studying adaptive evolution within the 'multivariate space' of natural conditions (Hoffmann \& Sgró 2011) to assess its relevance for ongoing climate change (Merilä \& Henry 2014; Franks et al. 2014, 2018).

In plants, the limited number of tests for rapid evolution under changing climate under near-natural conditions focused on two approaches. One is the resurrection approach, where stored seeds collected years before within a plant community are revived and compared to plants from recently sampled seeds from the same location (reviewed in Franks et al. 2018). Yet, this approach cannot unambiguously isolate climate as the causal factor for observed changes (Frankset al. 2018). Another approach is multi-year climate manipulations imposed on natural communities in the field. When plants are subsequently screened for divergent evolution, as a key asset, changes can be attributed directly to contrasting climatic treatments as the causal factor. 
Only few studies followed this highly demanding approach, reporting evolutionary change in some genetic markers (Jumpet al . 2008, Ravenscroft et al . 2015) or certain phenotypic traits (Grossman \& Rice 2014, Ravenscroft et al . 2014, Nguyen et al . 2016).

With either approach it remains a great challenge though to judge whether observed changes are adaptive. This judgement is often done a posteriori based on 'intuition' or 'common sense' (Merilä \& Hendry 2014, Franks et al . 2018). Yet, since species can adapt via different sets of traits to the same climatic challenge (e.g. Biltonet al . 2016, Bergholz et al . 2017, Lampei et al . 2017 for aridity), the set of traits expected to evolve can likewise differ among species. Moreover, Sandel et al. (2010) cautioned that initial trait responses to a changing climate may differ from those for long-term adaptation. These complexities may render commonsense interpretations misleading, i.e. we need much clearer justifications to conclude adaptive responses.

Here, we addressed this challenge using several independent lines of evidence simultaneously. Firstly, we imposed replicated climate manipulations in situ on entire plant communities to control directly the causal factor, and we did so in two independent sites. Consistent evolutionary responses in both sites would then strongly argue against random drift effects and in favor of adaptivity. Secondly, we combined these climate manipulations with a corresponding natural climatic gradient in a 'space-for-time' approach: Many species show clinal trait divergence along natural gradients when grown under common garden conditions, including our study species (e.g. Kigel et al . 2011, Petrů et al . 2006, Lampei et al . 2017). Such clines likely reflect locally adapted ecotypes, i.e. the species-specific long-term adaptive strategy towards the corresponding climatic factor (Kawecki \& Ebert 2004), and hence provide clear a prioripredictions for directional trait evolution under climate manipulations. Thirdly, we based our selection of study traits on evolutionary theory, i.e. attested evidence for theoretical fitness advantages under differential climatic conditions. Lastly, we performed additional selection analyses on target plants grown in the greenhouse, yet under a set of contrasting abiotic conditions that mirrored our in situclimate manipulations. If the covariance between trait values and relative fitness changes with climatic condition, differential trait values should be advantageous contingent on climate (Lande \& Arnold 1983). By combining these multiple approaches, we gained unprecedented strong evidence for whether potential evolutionary changes are adaptive.

Another recent debate addresses the role of phenotypic plasticity in climate change adaptation (e.g. Merilä \& Henry 2014, Kelly 2019, Foxet al . 2019, Acasuso-Rivero et al . 2019). Climate change imposes novel conditions on plants in local communities. High plasticity in adaptive traits, as an immediate response to altered environments, may help genotypes to match their phenotype to these novel conditions (Chevin et al . 2010; Kelly 2019). Therefore, climate change may theoretically target plasticity itself for evolution and favor more plastic genotypes within the population; even if this is a transient response that is merely 'buying time' until the occurrence of new genotypes with specific adaptations to the new conditions (Crispo 2007; Lande 2009; Merilä \& Henry 2014; Fox et al . 2019). However, explicit tests for increased plasticity under climate change are extremely scarce, and experimental evidence from natural populations is lacking (Kelly 2019). Of 12 resurrection studies reviewed recently (Franks et al. 2018) and the six studies with long-term climate manipulation mentioned above, only three have tested for rapid evolution of plasticity. They found reduced (Grossman \& Rice 2014) or unchanged plasticity (Franks 2011) with altered climate. This knowledge gap is unfortunate because moreover, plasticity may also interact with genetic adaptation by buffering selection and hence slowing down evolution and genetic adaption (Merilä \& Hendry 2014, Kelly 2019, Fox et al . 2019), i.e. rapid evolution may be confined to traits with low plasticity. Yet, no previous study has systematically compared rapidly evolving traits with their degree of plasticity.

To address these gaps, we conducted a uniquely comprehensive test for rapid evolution in ten target traits and their plasticity in a large-scale, multi-site climate change experiment (Tielbörger et al . 2014). Experimental rainfall manipulations $(+30 \%$, control, $-30 \%)$ where imposed for ten years in two sites on entire resident plant communities in the Eastern Mediterranean, and combined with a natural rainfall gradient. Rainfall is the key abiotic factor in these ecosystems, with a projected -20\% decline until 2050 (Smiatek et al . 2011; Samuels et al . 2013). Annual species dominate these communities, which allows for potentially rapid evolutionary responses (Tielbörger et al . 2014). Since migration of most species is limited (Siewert \& Tielbörger 2010), 
in situ evolution may be crucial for climate change adaptation. We tested for evolutionary divergence in traits and plasticity in a naturally occurring annual plant species after ten years of climate manipulations, and used trait clines along the rainfall gradient and selection analyses across greenhouse irrigation levels to judge adaptivity. We hypothesized that ten years of climate manipulation had caused adaptive evolutionary trait divergence and selection for higher plasticity, and that evolution was retarded in highly plastic traits.

\section{MATERIALS AND METHODS}

\section{Field sites and climate change manipulations}

Four field sites were chosen along a natural rainfall gradient from Northern to Southern Israel which share most abiotic characteristics except for mean and variance in rainfall conditions (details in Tielbörger et al. 2014). The sites share a Mediterranean-type climate and similar mean annual temperature (17.7-19.1 $\left.{ }^{\circ} \mathrm{C}\right)$, yet spanned a more than eight-fold difference in mean annual rainfall. They represent mesic-Mediterranean (MM, $780 \mathrm{~mm}$ rainfall, $\left.33^{\circ} 00^{\prime} \mathrm{N}, 35^{\circ} 14^{\prime} \mathrm{E}\right)$, Mediterranean (M, $\left.540 \mathrm{~mm}, 31^{\circ} 42^{\prime} \mathrm{N}, 35^{\circ} 03^{\prime} \mathrm{E}\right)$, semi-arid (SA, 300 $\left.\mathrm{mm}, 31^{\circ} 23^{\prime} \mathrm{N}, 34^{\circ} 54^{\prime} \mathrm{E}\right)$ and arid conditions (A, $\left.90 \mathrm{~mm}, 30^{\circ} 52^{\prime} \mathrm{N}, 34^{\circ} 46^{\prime} \mathrm{E}\right)$, respectively. The length of the rainy season increases from the driest (Dec/Jan-March) to the wettest site (Oct/Nov-May), while rainfall variability among years decreased from the driest (40\% Coefficient of Variation) to the wettest site $(25 \%$ CV) (Metz et al. 2018). All sites are semi-natural shrublands with mostly annual species in the inter-shrub matrix, located at south exposures on limestone bedrock with similar elevation (470-620 m a.s.l.).

Three rainfall manipulation treatments (dry, control, wet) were imposed on entire resident plant communities for ten years (2002-2012) in the two intermediate sites, M and SA. Each treatment was replicated by five randomized $10 \mathrm{~m} \times 25 \mathrm{~m}$ plots per site. The two extreme sites, A and MM, contained only five control plots each and extended the range of the natural rainfall gradient. For dry manipulation, rainout shelters intercepted $30 \%$ of each rainfall event; for wet manipulation, additional sprinkler irrigation after every other rain event added in total $30 \%$ of the site's long-term average rainfall per year; control plots received ambient rainfall (details in Tielbörger et al.2014). The magnitude of the dry manipulations approximated climate change scenarios for our study region, predicting 20\% less rainfall until 2050 (Smiatek et al.2011; Samuels et al . 2013), while the wet manipulations extended the general range of scenarios.

\section{Study species, seed sampling and amplification}

We focused on Biscutella didyma L., a winter annual Brassicaceae with Mediterranean and Irano-Turanian distribution (Feinbrun-Dothan \& Danin 1998). It was selected because it is one of few species occurring commonly across the entire rainfall gradient. As is typical for many annuals in our study region, B. didyma has short dispersal distances (Siewert \& Tielbörger 2010) and low outcrossing rates (Boazet al. 1990), making gene-flow among manipulated plots unlikely.

Seeds of B. didyma were collected in spring 2012 from twenty randomly selected individuals within each $10 \mathrm{~m} \times 25 \mathrm{~m}$ plot, i.e. 100 per rainfall treatment and site. From these seeds, one offspring per individual was raised with regular watering for one generation in Tübingen (Germany) to reduce potential parental effects. The growth period (Nov 2012 - May 2013) approximated the natural vegetation season and photoperiod, and greenhouse temperatures mirrored day temperatures in the field sites $\left(15-20{ }^{\circ} \mathrm{C}\right.$ in winter, gradually warming to $25-30^{\circ} \mathrm{C}$ in spring). Wrapping flowering plants in light, transparent fabric (organza) ensured selfpollination and seed collection separately per mother. Of the resulting second-generation seed material, we randomly picked 40 mothers (hereafter 'genotypes') per rainfall treatment and site (in total 320 genotypes) for the subsequent greenhouse experiment.

\section{Greenhouse experiment}

One season later (Nov $22^{\text {nd }} 2013$ - May $15^{\text {th }} 2014$ ), we raised these 320 genotypes under conditions as above in the same greenhouse, yet under five water levels. One pot $(10 \times 10 \times 10 \mathrm{~cm})$ per genotype was included in each water level (1600 pots in total). Per pot, 15 seeds of one genotype were sown in a 1:1 mixture of nutrient-poor potting soil and sand, enriched with $0.1 \mathrm{~g}$ Osmocote $\mathbb{R}$ slow release fertilizer (14-14-14 NPK; Scotts GmbH, Nordhorn, Germany). 
On the first and third day of the experiment, all pots were watered equally to saturation to ensure sufficient seed germination. After germination was completed, seedlings were randomly thinned to one per pot and five watering levels were initiated $(90 \mathrm{ml}, 50 \mathrm{ml}, 30 \mathrm{ml}, 20 \mathrm{ml}$, and $15 \mathrm{ml}$ per pot and watering event, respectively). Watering was applied manually with dispensers approx. every 2-3 days, i.e. when most plants in the lowest water level showed strong signs of drought stress. Pots were randomized across the greenhouse and re-randomized every three weeks.

\section{Phenotyping}

We focused on ten traits related to differential water availability across the entire plant life-cycle.

Germination fraction was censused per pot after germination had ceased at the beginning of the experiment. It typically decreases towards arid populations to hedge against more frequent unfavorable years (Tielbörger et al . 2012; Lampei et al. 2017; ten Brink et al. 2020). As climate manipulations increased (dry plots) and decreased (wet plots) the occurrence of unfavorable years, we expected reduced germination fractions being favored in dry plots andvice-versa in wet plots.

Days to flowering (since first irrigation) were determined by inspecting plants daily for the first open flower. Accelerated phenology is expected by theory and repeatedly found in annual plants from drier sites (reviewed in Kigel et al. 2011), and we expected earlier phenology in plants descending from dry manipulated plots and more arid sites. Moreover, the number of leaves at the day of first flowering (leaf number at flowering ) provided an ontogenetic phenological measure and a non-destructive measure of plant size. It disentangled whether phenology changed via accelerated development (days to flowering) or shifted ontogeny (leaves at flowering) (Kigel et al . 2011).

Stomata density and carbon isotopes $\left(\delta^{13} \mathrm{C}\right)$ assessed gas exchange and water use efficiency. Stomata density was quantified by automated high-throughput microscopy (Dittberner et al. 2018; see Supplementary Methods). As lower stomata density may decrease maximum transpiration (Liuet al ., 2012) we expected lower stomata density in plants descending from drier conditions. Due to high costs, carbon isotopic ratios $\left(\delta^{13} \mathrm{C}\right.$, see supplementary Methods), were analyzed only for a subset (14 genotypes per site, rainfall treatment, and four water levels: $15 \mathrm{ml}-50 \mathrm{ml})$. We expected that plants from drier sites and plots exhibit higher water use efficiency, i.e. higher $\delta{ }^{13} \mathrm{C}$ (Li 1999; Hartman \& Danin 2010).

Plant height was measured on a fixed day $\left(12^{\text {th }}\right.$ April $)$ before the onset of senescence. Moreover, abovegroundvegetative biomass was determined at the end of the experiment (May 15 ${ }^{\text {th }}$ 2014) as the dry weight $\left(24 \mathrm{~h}, 70^{\circ} \mathrm{C}\right)$ of all stems and leaves. We expected greater height and vegetative biomass in plants from wetter conditions as adaptation to intensified aboveground competition (Westoby 1998; Schiffers \& Tielbörger 2006).

Total seed number per plant quantified fitness. Moreover, we estimated the selfing rate per plant visually as percent of flowers that developed into viable seeds; it served as covariate in some analyses because $B$. didyma populations may differ in self-compatibility (Gibson-Forty 2018).

Reproductive allocation quantified the biomass allocation to reproductions (i.e. weight of all diaspores and flower remains) relative to the vegetative biomass. Reproductive allocation should be higher in plants from drier conditions as they require less investment in vegetative tissue for outgrowing neighbors (Aronson et al. 1993).

Diaspore weight (maternal investment per single offspring) was measured across 30 randomly picked diaspores per plant. Diaspore weight consists of c. $50 \%$ of seed mass in B. didyma and both are strongly correlated $\left(\mathrm{r}^{2}=0.88, \mathrm{p}<0.001\right.$; determined for 15 seeds in 32 randomly picked individuals across sites $)$. Although investment per offspring is a crucial feature of plant life cycles (Westoby 1998), predicting its evolutionary response to aridity is controversial (Kurzeet al. 2017).

Statistical analyses

Analyses of the above trait values were performed in four steps with R 3.5.2 (R core team 2018). 
First, we tested for divergent trait evolution in plants descending from dry, control and wet manipulated plots in the central sites SA and M. For each trait separately, linear mixed models were calculated with climate change manipulation (dry, control, wet), site (SA, M), the five greenhouse watering levels, and their interactions as fixed factors, as well as genotype as random factor. Some traits were transformed prior to analyses to meet homoscedasticity (sqrt: stomata density, height, reproductive allocation, seed number; log: leaf number at flowering, vegetative biomass). Significance was assessed with Chi-square tests in the package car (Fox \& Weisberg 2011) and posthoc tests identified contrasting climate manipulations using the package 'multcomp' (Hothorn et al. 2008) with P-values corrected for false discovery rate (FDR) sensu Benjamini \& Hochberg (1995). For germination fraction (binary) we used a corresponding glm with logit link-function and quasibinomial error structure.

Second, we tested for clinal trends in traits across the rainfall gradient, including only plants descending from control plots in all four sites. We calculated linear mixed models per trait with site and greenhouse water level as fixed factors, and genotype as random factor (transformations as above). Posthoc tests with FDR-correction as above identified contrasting sites. Germination fraction was analyzed with a binomial glm as above, using only site as main factor.

Third, we applied selection analyses for trait responses to low and high irrigation in the greenhouse. They assessed adaptivity of traits without environmental factors that may correlate with water availability under natural conditions (Mitchell-Olds \& Schmitt 2006; De Frenne et al. 2013). We ran selection analyses for all traits showing either rapid evolution (first step) or clines with rainfall (second step). We included all plants from sites with climate manipulation, computed genotype mean trait values separately across low watering $(15 \mathrm{ml}, 20 \mathrm{ml})$ and high watering $(50 \mathrm{ml}, 90 \mathrm{ml})$, followed by normalization (zero mean, $1 \mathrm{SD}$ ) per population (SA and M) and watering level. Similarly, relative fitness was computed per population for high and low watering. We fitted generalized least squares models (gls, rms package (Harrell 2019)), with relative fitness as the dependent variable and trait value, water availability (high, low) and their interaction as predictors. A significant trait value $\times$ water interaction indicated contrasting directional selection on that trait contingent on water availability (Lande \& Arnold 1983), computed using type III sums of squares (Anova, car package (Fox \& Weisberg 2019)).

Fourth, we tested whether climate manipulations favored genotypes with higher plasticity. Plasticity was quantified for the above traits using the Coefficient of Variation (CV) across the five individuals (i.e. water levels) per genotype in the greenhouse. $\mathrm{CV}$ is s a standardized parameter that allows comparing plasticity across traits of different units and scales (Houle 1992; Acasuso-Rivero et al . 2019). With these CV-values per genotype, we calculated two-way ANOVAs and FDR-post hoc tests separately for each trait, including the factors site (SA, M) and climate change treatment (dry, control, wet).

\section{RESULTS}

\section{Rapid trait evolution under climate manipulations}

Three out of ten traits showed significant divergence among climate manipulations and hence rapid evolution within 10 years of field experiments. It was always the dry treatment that had diverged from control and wet treatments (Table 1, Fig. 1). Plants descending from dry manipulated plots flowered on average 3-4 days (c. 4\%) earlier and with 4-5 (c. 13\%) fewer leaves, and had 10-15\% higher reproductive allocation than plants from control and wet manipulated plots (Table 1, Fig. 1). These evolutionary responses to drought were consistent in both sites (no site $\times$ climate manipulation and site $\times$ water $\times$ climate manipulation interactions; Table 1).

The seven remaining traits showed no divergence among climate manipulation treatments (Table 1, Fig. 1).

\section{Trait divergence along the rainfall gradient}

Eight traits showed significant clinal trends across the natural rainfall gradient, suggesting an adaptive role for these traits with rainfall. Towards drier sites, plants decreased in germination fraction, days to flowering, stomata density, height, and biomass, and they increased in reproductive allocation and seed production 
(Table 2, Fig. 1). Furthermore, flowering started at smaller plant size (fewer leaves) in drier sites, although at MM, plants invested less in lateral branches and thus possessed fewer but larger leaves along the main stem (Petrů et al . 2006; pers. obs.). There was a marginally significant tendency towards lower ${ }^{13} \mathrm{C}$ in arid sites ( $\mathrm{p}=0.08$, Fig. 1$)$ and no clinal trend for diaspore weight despite significant differences among sites (Table 2, Fig. 1).

The clinal trends across sites in flowering time, leaf number at flowering and reproductive allocation matched the direction of their rapid evolutionary response within ten years climate manipulation. In contrast, five traits showed clines along the natural rainfall gradient but no rapid evolution under climate manipulations (germination fraction, stomata density, height, biomass, seed number).

The five water levels in the greenhouse affected all traits (Table $1 \& 2$; Fig. S1 supp. information), indicating plasticity in response to water. Clearly significant site $\times$ water interactions for all traits except reproductive allocation $(\mathrm{p}=0.08)$ indicated genetic variation in trait plasticity among sites (Table 2 ).

\section{Selection analyses}

Selection on several traits differed between low and high watering in the greenhouse (Fig. 2). As in the field experiment, days to flowering and leaf number at flowering experienced stronger directional selection under low water availability (water availability $\times$ days to flowering: $\chi^{2}=13.6, \mathrm{df}=1, \mathrm{p}<0.001, \mathrm{~b}_{\text {low }}=-0.3, \mathrm{~b}_{\text {high }}=-$ 0.08 ; water availability $\times$ leaf number at flowering: $\left.\chi^{2}=9.4, \mathrm{df}=1, \mathrm{p}=0.002, \mathrm{~b}_{\text {low }}=-0.24, \mathrm{~b}_{\text {high }}=-0.1\right)$. The third trait showing rapid evolution, reproductive allocation, was generally under strong selection due to its close correlation with relative fitness (Fig. 2); yet a significant interaction with water availability indicated that high reproductive allocation was more favored under low than under high watering $\left(\chi^{2}=114.6, \mathrm{df}=1\right.$, $\left.\mathrm{p}<0.001, \mathrm{~b}_{\text {low }}=0.7, \mathrm{~b}_{\text {high }}=0.35\right)$.

Among traits without significant rapid evolution, vegetative biomass was stronger selected against under low water availability than under high water availability $\left(\chi^{2}=17.1, \mathrm{df}=1, \mathrm{p}<0.001\right.$, Fig. 2). Because this negative correlation with relative fitness $(b=-0.24)$ disappeared $(b=0.01)$ when reproductive allocation was added to the model, this may be an indirect effect driven by the observed selection for high reproductive allocation. No differential selection was found for stomata density $\left(\chi^{2}=2.16, \mathrm{df}=1, \mathrm{p}=0.14\right.$, Fig. 2$)$ and for plant height, where tall plants were favored alike under low and high water availability (Fig. $2, \chi^{2}=0.21$, $\mathrm{df}=1, \mathrm{p}=0.65)$.

\section{Plasticity under climate manipulations}

The Coefficient of Variation (i.e degree of plasticity) differed substantially among traits. CV was lowest in $\delta$ ${ }^{13} \mathrm{C}(3-4 \%)$ and days to flowering (c. 10\%), intermediate for diaspore weight, height, stomata density, leaf number at flowering and total biomass, and particularly high in reproductive allocation (c. 80\%) and seed number (c. 100\%) (Fig. 3). There was no apparent relation between plasticity and the probability of rapid evolution in the field as the three traits showing rapid evolution had low (days to flowering), intermediate (leaf number at flowering) and high plasticity (reproductive allocation), respectively.

Climate manipulations had overall little effect on plasticity. A tendency for increased plasticity in plants from dry manipulated plots compared to controls was found in diaspore weight $(\mathrm{p}=0.01)$ and marginally for days to flowering $(\mathrm{p}=0.06)$ (Table 3 , Fig. 3$)$. In vegetative biomass, plasticity was significantly increased in dry plots $(\mathrm{p}=0.03)$, but only in comparison to wet plots (Table 3, Fig. 3). The lack of any significant climate manipulation $\times$ site interaction showed that plasticity responded similarly in both sites (Fig. 3, Table 3).

Plasticity was significantly higher in the Mediterranean than the semi-arid site in four traits: days to flowering, height, reproductive allocation, seed number (Table 3, Fig. 3).

\section{DISCUSSION}

Our overall results demonstrate rapid evolution in three out of ten traits under in situ climate manipulations in natural plant communities after merely 10 years, i.e. at most 10 generations of our annual study species. This is a remarkably short time span, given that numerous interacting factors may hamper evolution in 
natural communities (Hoffmann \& Sgró 2011; Shaw \& Etterson 2012). The fact that this evolutionary response was consistent in two independent sites renders chance effects, e.g. genetic drift, unlikely to have affected these results and underpins that the evolutionary response was directly driven by manipulated rainfall. Intriguingly, our multiple independent lines of evidence corroborate that these changes were adaptive.

After 10 years of artificial drought, phenology had evolved in chronological time (days to flowering) and ontogenetic time (leaf number at flowering). Theory suggests accelerated life-cycles as a drought avoidance strategy that reduces the risk of mortality before reproduction (Cohen 1976; Kigel et al. 2011). Yet, early reproduction comes at the cost of smaller plant size and hence possibly lower competitive ability (Liancourt \& Tielbörger 2009; Kigel et al. 2011). In line with theory, plants from dry-manipulated plots flowered earlier and with fewer leaves than plants from control and wet plots. Moreover, this rapid evolutionary response paralleled the long-term evolutionary response of $B$. didyma along the natural rainfall gradient where plants from more arid sites flowered earlier; a trend found in many other annuals along natural rainfall gradients (Stinchcombe et al. 2004; Kigel et al . 2011; Wolfe \& Tonsor 2014; Kurze et al . 2017). Interestingly, the observed 3-4 days acceleration in phenology corresponds to an ecological distance of c. $100 \mathrm{~mm}$ lower rainfall at origin for annuals along our study gradient (Kigel et al . 2011; Kurze et al. 2017). Given the magnitude of rainfall reduction in dry plots $(-90 \mathrm{~mm}$ in SA, $-160 \mathrm{~mm}$ in $\mathrm{M})$, this suggests that a substantial part of the 'required' acceleration in phenology could be realized within ten years. The adaptivity of accelerated phenology under drought was furthermore corroborated by our selection analyses under controlled watering conditions in the greenhouse, which eliminated potentially confounding factors along natural environmental gradients (Mitchell-Olds \& Schmitt 2006, De Frenne et al. 2013). Here, earlier flowering with fewer leaves was stronger favored under low than under high water availability. These multiple lines of evidence - theory, natural rainfall gradient, selection analyses, and consistency in both sites - provide compelling evidence that the observed rapid evolution in phenology was adaptive.

Rapid evolution of earlier flowering under drought was found also in other climate change studies; it is thus far the trait most often reported to evolve under drought in natural conditions (Franks et al. 2007; Vigouroux et al . 2011; Nevo et al. 2012; Nguyenet al. 2016). Accelerated phenology therefore emerges as a key pathway for rapid evolutionary adaptation to drier climates. While this underpins the central role of phenology for drought adaptation in annuals (Cohen 1976; Kigel et al. 2011; Kurze et al.2017), it may also signpost that phenology evolves easier than other, possibly more complex traits. However, this conclusion is still hampered by the few tests beyond our study reporting multiple traits besides phenology (Ravenscroft et al. 2014; Nguyen et al. 2016).

Here, we also observed rapid evolution in reproductive allocation. As competition is reduced in drier sites along our gradient (Schiffers \& Tielbörger 2006), theory suggests reduced investment in vegetative tissue for outgrowing neighbors and increased allocation to reproduction (Aronson et al. 1990; 1993). In line with theory and in both sites, plants from dry manipulated plots produced 10-15\% more seeds per vegetative biomass than control plants. Although reproductive allocation was rarely assessed in climate manipulation studies, a similar evolutionary tendency was reported for a perennial herb (Ravenscroftet al . 2014). This evolutionary response was again congruent with our selection analyses in the greenhouse, and it matched the clinal trend in reproductive allocation along our natural rainfall gradient, and parallel clines in other species (summarized in Kurze et al.2017). Thus, in all traits showing rapid evolution in the field, our independent lines of evidence demonstrate that these changes were adaptive. Intriguingly, parallel studies had reported remarkable resistance in many plant community parameters to imposed climate manipulations (Tielbörger et al . 2014; Bilton et al . 2016). The present findings highlight that rapid adaptive evolution played an important role for climate change responses in annual species, and probably contributed significantly to community resistance.

Notably, all evolutionary changes occurred solely in the dry manipulated plots, i.e. the treatment which increased, rather than decreased stress for resident plants. This appears intuitive because drought may directly lead to rapid exclusion of drought-sensitive and late-flowering genotypes, especially in dry study years. In wet plots, selection among genotypes was probably driven by competition for additional resources 
(Schiffers \& Tielbörger 2006), resulting in weaker, more gradual fitness differences, as was shown for $B$. didyma in a cross-transplant with and without competition (Ariza \& Tielbörger 2011), and hence slower progression of exclusion and adaptive evolution.

However, seven further candidate traits did not evolve. This is surprising because five of them exhibited clinal shifts along the natural rainfall gradient, suggesting that they contribute to $B$. didyma's long-term evolutionary response to drier climates: germination fraction, stomata density, height, vegetative biomass and seed number. In conjunction with existing theory we had expected corresponding evolution of these traits under climate manipulations (Westoby 1998; Liuet al. 2012; Tielbörger et al. 2012; ten Brink et al. 2020). Selection analyses supported this expectation for vegetative biomass, although not for stomata density and height, and they were not possible for germination fraction (no differential watering) and seed number (response variable in selection analyses). One possible explanation for the lack of evolution in other candidate traits is that sufficient adaptation was ensured by those traits that did evolve, and hence evolution of further traits was unnecessary. Alternatively, the multiple potential constraints for evolution under natural conditions hindered adaptation in other traits (Hoffmann \& Sgró 2011; Shaw \& Etterson 2012). In that case, the observed rapid evolution in a subset of traits may indicate incomplete adaptation to new conditions, cautioning that climate change may imperil species despite rapid evolution. Unfortunately, almost all available evidence for rapid evolution under natural conditions was restricted to very few traits (e.g. Franks et al. 2018; Nguyen et al . 2016; Grossmanet al. 2014; but see Frachon et al. 2017), i.e. there is lacking information and focus on the importance of non-evolving traits for adaptation to climate change. Our results thus highlight that studies relying on few traits might be misleading.

High trait plasticity was intensely debated as a mechanism retarding adaptive evolution to climate change, yet rarely tested in nature (Merilä \& Hendry 2014; Kelly 2019; Fox et al. 2019). Here, each of the three rapidly evolving traits had a completely different degree of plasticity. This first assessment under field conditions suggests that traits may evolve rapidly irrespective of their degree of plasticity, and that rapid evolution appears rather restricted by other mechanisms such as the genetic architecture of traits, potential underlying trade-offs, or limited genetic variation within populations (Barrett \& Schluter 2007; Hoffmann \& Sgró 2011; Shaw \& Etterson 2012). Our findings furthermore give little support for the idea that climate change leads to increased plasticity as a means to rapidly adjust the phenotype to novel conditions (Crispo 2007; Lande 2009; Merilä \& Hendry 2014; Kelly 2019, Fox et al. 2019), because only a single trait (diaspore weight) showed increased plasticity under drought. Evolution of increased plasticity is therefore unlikely to be a pathway for climate change adaptation in our system, corroborating the few existing climate change studies which found plasticity either unchanged (Franks 2011) or lower (Grossman \& Rice 2014).

Overall, our study demonstrates that rapid evolution plays an important role for climate change adaptation in natural annual plant communities. The novel setup of our study - combining for the first time in situ climate manipulations with a natural climatic gradient and selection analyses under controlled conditions - provided independent, compelling lines of evidence that observed evolutionary shifts were adaptive. However, with rapid evolution in merely a subset of candidate traits, our study emphasizes the importance of multi-trait studies for assessing whether rapid in situ evolution may safeguard species under climate change.

\section{ACKNOWLEDGEMENTS}

We are grateful to a very large number of ambitious students and colleagues who helped at various stages of this long-term experiment. The field experiment was part of the GLOWA Jordan River project, funded by the German Ministry of Education and Research (BMBF) and further supported by the DFG SPP 1529 (Adaptomics) of the German Research Foundation (TI338/11-1 and TI338/11-2 to KT, ME 2742/6-1 to JdM and INST 211/575-1 to WWU Münster).

\section{DATA ACCESSIBILITY STATEMENT}

The data supporting our results are publicly available at the dryad.org data repository.

\section{REFERENCES}


Acasuso-Rivero, C., Murren, C.J., Schlichting, C.D. \& Steiner, U.K. (2019). Adaptive phenotypic plasticity for life history and less fitness-related traits. Proc. R. Soc. B , 286, 20190653.

Ariza, C. \& Tielbörger, K. (2011). An evolutionary approach to studying the relative importance of plantplant interactions along environmental gradients. Funct. Ecol. , 25, 932-942.

Aronson, J., Kigel, J. \& Shmida, A. (1990). Comparative plant sizes and reproductive strategies in desert and Mediterranean populations of ephemeral plants. Isr. J. Bot . 39, 413-430.

Aronson, J., Kigel, J. \& Shmida, A. (1993). Reproductive allocation strategies in desert and Mediterranean populations of annual plants grown with and without water stress. Oecologia, 93, 336-342.

Barrett, R.D.H. \& Schluter, D. (2007). Adaptation from standing genetic variation. Trends Ecol. Evol ., 23, $38-44$.

Benjamini, Y. \& Hochberg, Y. (1995). Controlling the false discovery rate: a practical and powerful approach to multiple testing. Journal of the Royal Statistical Society Series B , 57, 289-300.

Bergholz, K., May, F., Ristow, M., Giladi, I., Ziv, Y. \& Jeltsch, F. (2017). Two Mediterranean annuals feature high within-population trait variability and respond differently to a precipitation gradient.Basic Appl. Ecol. , 25, 48-58.

Bilton, M., Metz, J. \& Tielbörger, K. (2016). Climatic niche groups: A novel application of a common assumption predicting plant community response to climate change. Persp. Plant Ecol. Evol. System. , 19, 61-69.

Boaz, M., Plitmann, U. \& Heyn, C.C. (1990). The ecogeographic distribution of breeding systems in the Cruciferae (Brassicaceae) of Israel. Isr. J. Bot ., 39, 31-42.

Chevin, L.M., Lande, R. \& Mace, GM. (2010). Adaptation, Plasticity, and Extinction in a Changing Environment: Towards a Predictive Theory.PLoS Biol., 8, e1000357.

Cohen, D. (1976). The optimal timing of reproduction. Am. Nat ., 110, 801-807.

Dittberner, H., Korte, A., Mettler-Altmann, T., Weber, A.P.M., Monroe, G. \& de Meaux, J. (2018). Natural variation in stomata size contributes to the local adaptation of water-use efficiency in Arabidopsis thaliana . Molecular Ecology, 27, 4052-4065.

Feinbrun-Dothan, N. \& Danin, A. (1998). Analytical Flora of Eretz-Israel, 2nd edn. CANA Publishing House Ltd., Jerusalem.

Fox, R.J., Donelson, J.M., Schunter, C., Ravasi, T. \& Gaitan-Espitia, J.D. (2019). Beyond buying time: the role of plasticity in phenotypic adaptation to rapid environmental change. Phil. Trans. R. Soc. B, 374, 20180174.

Fox, J. \& Weisberg, S.(2019). An $\{$ R $\}$ Companion to Applied Regression, Second Edition. Thousand Oaks CA: Sage.

Frachon, L., Libourel, C., Villoutreix, R., Carrere, S., Glorieux, C., Huard-Chauveau, C., et al . (2017). Intermediate degrees of synergistic pleiotropy drive adaptive evolution in ecological time.Nature Ecology $\mathcal{E}$ Evolution, DOI: 10.1038/s41559-017-0297-1.

Franks, S.J. (2011). Plasticity and evolution in drought avoidance and escape in the annual plant Brassica rapa. New Phytol. , 190, 249-257.

Franks, S,J., Hamann, E. \& Weis, A.E. (2018). Using the resurrection approach to understand contemporary evolution in changing environments. Evolutionary Applications , 11:17-28.

Franks, S.J., Sim, S. \& Weis, A.E. (2007). Rapid evolution of flowering time by an annual plant in response to a climate fluctuation.Proc. Natl Acad. Sci ., 104, 1278-1282. 
Franks, A.J., Weber, J.J. \& Aitken, S.N. (2014). Evolutionary and plastic responses to climate change in terrestrial plant populations. Evolutionary Applications , 7, 123-139.

De Frenne P., Graae, B.J., Rodriguez-Sanchez, F., Kolb, A., Chabrerie, O., Decocq, G., et al. (2013). Latitudinal gradients as natural laboratories to infer species' responses to temperature. J. Ecol. , 101, 784-795.

Gibson-Forty, E.V.J. (2018). Intraspecific Variation in Plant-Animal Interactions of the Brassicaceae Family Along a Steep Rainfall Gradient in the Eastern Mediterranean Basin. PhD Thesis, Tubingen, Germany. publikationen.uni-tuebingen.de

Grossman, J.D. \& Rice, K.J. (2014). Contemporary evolution of an invasive grass in response to elevated atmospheric CO2 at a Mojave Desert FACE site. Ecol. Lett. , 17, 710-716.

Harrell, F. (2019). rms: Regression Modeling Strategies. R package version 5.1-3.1. https://CRAN.Rproject.org $/$ package $=$ rms

Hartman, G. \& Danin, A., (2010). Isotopic values of plants in relation to water availability in the Eastern Mediterranean region. Oecologia , 162, 837-852.

Houle, D. (1992). Comparing Evolvability and Variability of Quantitative Traits. Genetics, 130, 195-204.

Hothorn, T., Bretz, F. \& Westfall, P. (2008). Simultaneous Inference in General Parametric Models. Biometrical Journal , 50, 346-363.

Jump, A.S., Penuelas, J., Rico, L., Ramallo, E., Estiarte, M, Martinez-Izquierdo, J.E, et al. (2008). Global Change Biol. , 14, 637-643.

Kawecki, T.J. \& Ebert, D. (2004). Conceptual issues in local adaptation. Ecol. Lett. , 7, 1225-1241.

Kelly M. (2019). Adaptation to climate change through genetic accommodation and assimilation of plastic phenotypes. Phil. Trans. R. Soc. B , 374, 20180176.

Kigel, J., Konsens, I., Rosen, N., Rotem, G., Kon, A. \& Fragman-Sapir, O. (2011). Relationships between flowering time and rainfall gradients across Mediterranean-desert transects. Isr. J. Ecol. Evol. , 57, 91-109.

Kurze, S., Bareither, N., \& Metz, J. (2017). Phenology, roots and reproductive allocation, but not the LHS scheme, shape ecotypes along an aridity gradient. Perspectives in Plant Ecology, Evolution and Systematics , 29, 20-29.

Lampei, C., Metz, J. \& Tielborger, K. (2017). Clinal population divergence in an adaptive parental environmental effect that adjusts seed banking. New Phytol ., 214, 1230-1244.

Lande, R. \& Arnold, S.J. (1983). The measurement of selection on correlated characters. Evolution, 37, $1210-1226$.

Li, C. (1999). Carbon isotope composition, water-use efficiency and biomass productivity of Eucalyptus microtheca populations under different water supplies. Plant and Soid , 214, 165-171.

Liancourt, P. \& Tielborger, K. (2009). Competition and a short growing season lead to ecotypic differentiation at the two extremes of the ecological range. Funct. Ecol ., 23, 397-404.

Liu, J., Zhang, F., Zhou, J., Chen, F., Wang, B. \& Xie, X. (2012). Phytochrome B control of total leaf area and stomatal density affects drought tolerance in rice. Plant Mol. Biol. , 78, 289-300.

Merila, J. \& Hendry, A.P. (2014). Climate change, adaptation, and phenotypic plasticity: the problem and the evidence. Evolutionary Applications , 7, 1-14.

Metz, J., Freundt, H. \& Jeltsch, F. (2018). Stable germination behavior but partly changing seed-seed interactions along a steep rainfall gradient. Basic Appl. Ecol. , 28, 5-16. 
Mitchell-Olds, T. \& Schmitt, J. (2006). Genetic mechanisms and evolutionary significance of natural variation in Arabidopsis.Nature, 441, 947-952.

Nevo, E., Fu, Y.B., Pavlicek, T., Khalifa, S., Tavasi, M. \& Beiles, A. (2012). Evolution of wild cereals during 28 years of global warming in Israel. Proc. Natl. Acad. Sci. , 109, 3412-3415.

Nguyen, M.A., Ortega, A.E., Nguyen, K.Q., Kimball, S., Goulden, M.L. \& Funk, J.L. (2016). Evolutionary responses of invasive grass species to variation in precipitation and soil nitrogen. J. Ecol ., 104, 979-986.

Petrů, M., Tielbörger, K., Belkin, R., Sternberg, M. \& Jeltsch, F. (2006). Life history variation in an annual plant under two opposing environmental constraints along an aridity gradient. Ecography , 29, 69-74.

R Core Team (2018). R: A language and environment for statistical computing. R Foundation for Statistical Computing, Vienna, Austria. URL https://www.R-project.org/.

Ravenscroft, C.H., Whitlock, R, Fridley, J.D. (2015). Rapid genetic divergence in response to 15 years of simulated climate change. Global Change Biol. , 21, 4165-4176.

Samuels, R., Harel, M. \& Alpert, P. (2013). A new methodology for weighting high resolution model simulations to project future rainfall in the Middle East. Clim. Res ., 57, 51-60.

Sandel, B., Goldstein, L.J., Kraft, N.J.B., Okie, J.G., Shuldman, M.I., Ackerly, D.D., et al. (2010). Contrasting trait responses in plant communities to experimental and geographic variation in precipitation. New Phytol., 188, 565-575.

Schiffers, K. \& Tielbörger, K. (2006). Ontogenetic shifts in interactions among annual plants. J. Ecol ., 94, $336-341$.

Shaw, R.G. \& Etterson, J.R. (2012). Rapid climate change and the rate of adaptation: insight from experimental quantitative genetics. New Phytol ., 195, 752-765.

Smiatek, G., Kunstmann, H. \& Heckl, A. (2011). High resolution climate change simulations for the Jordan River area. J. Geophys. Res ., 116, D16111.

Stinchcombe, J.R., Weinig, C., Ungerer, M., Olsen, K.M., Mays, C., Halldottir, S.S., et al. (2004). A latitudinal cline in flowering time in Arabidopsis thaliana modulated by the flowering time gene FRIGIDA. Proc. Natl. Acad. Sci. , 101, 4712-4717.

ten Brink, H., Gremer, J.R. \& Kokko, H. (2020). Optimal germination timing in unpredictable environments: the importance of dormancy for both among- and within-season variation. Ecol. Lett., doi: 10.1111/ele.13461.

Tielbörger, K., Bilton, M.C., Metz, J., Kigel, J., Holzapfel, C., Lebrija-Trejos, E., et al . (2014). Middleeastern plant communities tolerate 9 years of drought in a multi-site climate manipulation experiment. Nature Communications, 5, 5102 .

Tielbörger, K., Petrů, M. \& Lampei C. (2012). Bet-hedging germination in annual plants: a sound empirical test of the theoretical foundations. Oikos , 121, 1860-1868.

Vigouroux, Y., Mariac, C., De Mita, S., Pham, J.-L., Gérard, B., Kapran, I., et al. (2011). Selection for Earlier Flowering Crop Associated with Climatic Variations in the Sahel. PLoS ONE , 6, e19563.

Westoby, M., (1998). A leaf-height-seed (LHS) plant ecology strategy scheme. Plant and Soil , 199, 213-227.

Wood, S. \& Scheipl, F. (2014). gamm4: Generalized additive mixed models using mgcv and lme4.

Wolfe, M.D., \& Tonsor, S.J. (2014). Adaptation to spring heat and drought in northeastern Spanish Arabidopsis thaliana. New Phytol ., 201, 323-334.

\section{SUPPORTING INFORMATION}


Additional Supporting Information may be downloaded via the online version of this article at Wiley Online Library (www.ecologyletters.com).

Table 1 Linear mixed models testing for diverging trait values in plants originating from three Climate Change manipulations (CC) in two sites (semi-arid, Mediterranean) and grown under five water levels. For $C C$, posthoc results are provided to identify diverging treatments (dry, control, wet).

\begin{tabular}{|c|c|c|}
\hline & trait & $\mathrm{CC}$ manipulation $(\mathrm{df}=2)$ \\
\hline$\overline{\text { Germination }}$ & $\begin{array}{l}\text { Germination } \\
\text { germination fraction }\end{array}$ & $\mathrm{F}=0.033$ \\
\hline Phenology & $\begin{array}{l}\text { Phenology } \\
\text { days to flowering } \\
\text { leafs at flowering }\end{array}$ & $\begin{array}{l}\chi^{2}=9.30 \\
\chi^{2}=10.34\end{array}$ \\
\hline water \& gas exchange & $\begin{array}{l}\text { water \& gas exchange } \\
\text { stomata density } \\
\delta^{13} \mathrm{C}\end{array}$ & $\begin{array}{l}\chi^{2}=0.42 \\
\chi^{2}=4.83\end{array}$ \\
\hline Growth & $\begin{array}{l}\text { Growth } \\
\text { plant height } \\
\text { vegetative biomass }\end{array}$ & $\begin{array}{l}\chi^{2}=5.36 \\
X^{2}=0.94\end{array}$ \\
\hline Allocation & $\begin{array}{l}\text { Allocation } \\
\text { reprod. Allocation } \\
\text { diaspore weight }\end{array}$ & $\begin{array}{l}\chi^{2}=10.98 \\
\chi^{2}=4.36\end{array}$ \\
\hline Fitness & $\begin{array}{l}\text { Fitness } \\
\text { seed number } \\
{ }^{\circ} \mathrm{p}[?] 0.08,{ }^{*} \mathrm{p}<0.05,{ }^{* *} \mathrm{p}<0.01,{ }^{* * *} \mathrm{p}<0.001 \\
\mathrm{a} \text { model included covariate '\% selfing' }\left(\chi^{2}=554.18, \mathrm{df}=1, \mathrm{p}<0.0001\right) \\
{ }^{\mathrm{b}} \text { model included covariate '\% selfing' }\left(\chi^{2}=500.42, \mathrm{df}=1, \mathrm{p}<0.0001\right)\end{array}$ & $\begin{array}{l}\chi^{2}=3.73 \\
{ }^{\circ} \mathrm{p}[?] 0.08,{ }^{*} \mathrm{p}<0.05,{ }^{*} \mathrm{p}<0.0 \\
\text { a model included covariate, } \\
\text { b model included covariate, }\end{array}$ \\
\hline
\end{tabular}

Table 2 Linear mixed models testing for diverging trait values in plants originating from four sites along a natural rainfall gradient (including control plots only) and grown under five water levels. For site, posthoc results are provided to identify diverging sites (arid, semi-arid, Mediterranean, mesic-Mediterranean). Highlighted in bold are traits where trait divergence between sites followed a cline along the rainfall gradient.

\begin{tabular}{lll}
\hline & trait & site $(\mathrm{df}=3)$ \\
\hline Germination & $\begin{array}{l}\text { Germination } \\
\text { germination fraction }\end{array}$ & \\
Phenology & $\begin{array}{l}\text { Phenology } \\
\text { days to flowering }\end{array}$ & $\mathrm{F}=52.85$ \\
& leaves at flowering & $\chi^{2}=424.78$ \\
water \& gas exchange & water \& gas exchange & $\chi^{2}=54.46$ \\
& stomata density & \\
Growth & $\delta^{13} \mathrm{C}$ & $\chi^{2}=13.29$ \\
& Growth & $\chi^{2}=6.66$ \\
Allocation & plant height & $\chi^{2}=50.70$ \\
& vegetative biomass & $\chi^{2}=22.37$ \\
Fitness & Allocation & $\chi^{2}=81.81$ \\
& reprod. allocation & \\
& diaspore weight & $\chi^{2}=15.70$
\end{tabular}




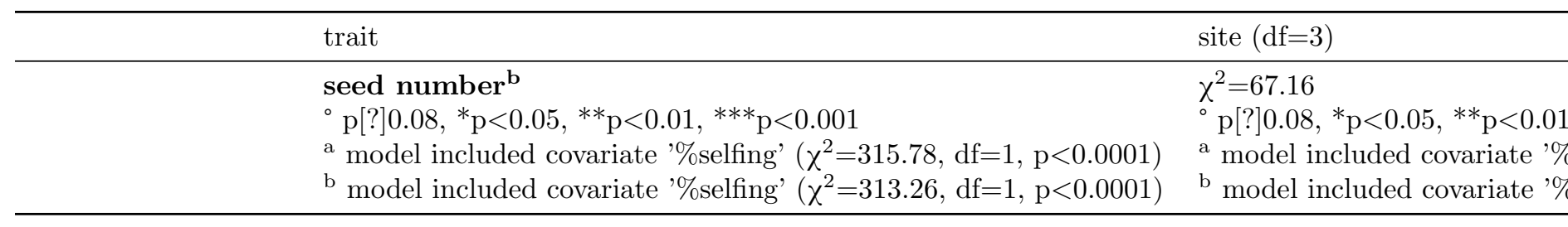

Table 3 Two-way ANOVAs testing for diverging plasticity (measured per genotype as Coefficient of Variation across five water levels) in nine traits of plants descending from three Climate Change manipulation treatments (CC) in two sites (semi-arid, Mediterranean). Posthoc results are provided to identify diverging CC treatments (dry, control, wet) and contrasting sites.

\begin{tabular}{|c|c|c|c|}
\hline & & $\mathrm{CC}(\mathrm{df}=2)$ & $\mathrm{CC}(\mathrm{df}=2$ \\
\hline & trait plasticity & $\mathrm{F}$ & \\
\hline \multirow[t]{3}{*}{ phenology } & phenology & & \\
\hline & days to flowering & 2.84 & $\circ$ \\
\hline & leaves at flowering & 1.38 & \\
\hline \multirow[t]{3}{*}{ water \& gas exchange } & water \& gas exchange & water \& gas exchange & \\
\hline & stomata density & 1.12 & \\
\hline & $\delta 13 \mathrm{C}$ & 0.22 & \\
\hline \multirow[t]{3}{*}{ growth } & growth & & \\
\hline & height & 0.17 & \\
\hline & veg. biomass & 3.47 & $* \mathrm{~d}>\mathrm{w}$ \\
\hline \multirow[t]{3}{*}{ allocation } & allocation & & \\
\hline & reprod. allocation & 0.98 & \\
\hline & diaspore weight & 4.57 & $* \mathrm{~d}>\mathrm{c}, \mathrm{w}$ \\
\hline \multirow[t]{3}{*}{ fitness } & fitness & & \\
\hline & seed number & 0.02 & \\
\hline & ${ }^{\circ} \mathrm{p}<0.08,{ }^{*} \mathrm{p}<0.05,{ }^{* *} \mathrm{p}<0.01,{ }^{* * *} \mathrm{p}<0.001$ & ${ }^{\circ} \mathrm{p}<0.08,{ }^{*} \mathrm{p}<0.05,{ }^{*} \mathrm{p}<0.01, * * * \mathrm{p}<0.001$ & ${ }^{\circ} \mathrm{p}<0.08$ \\
\hline
\end{tabular}



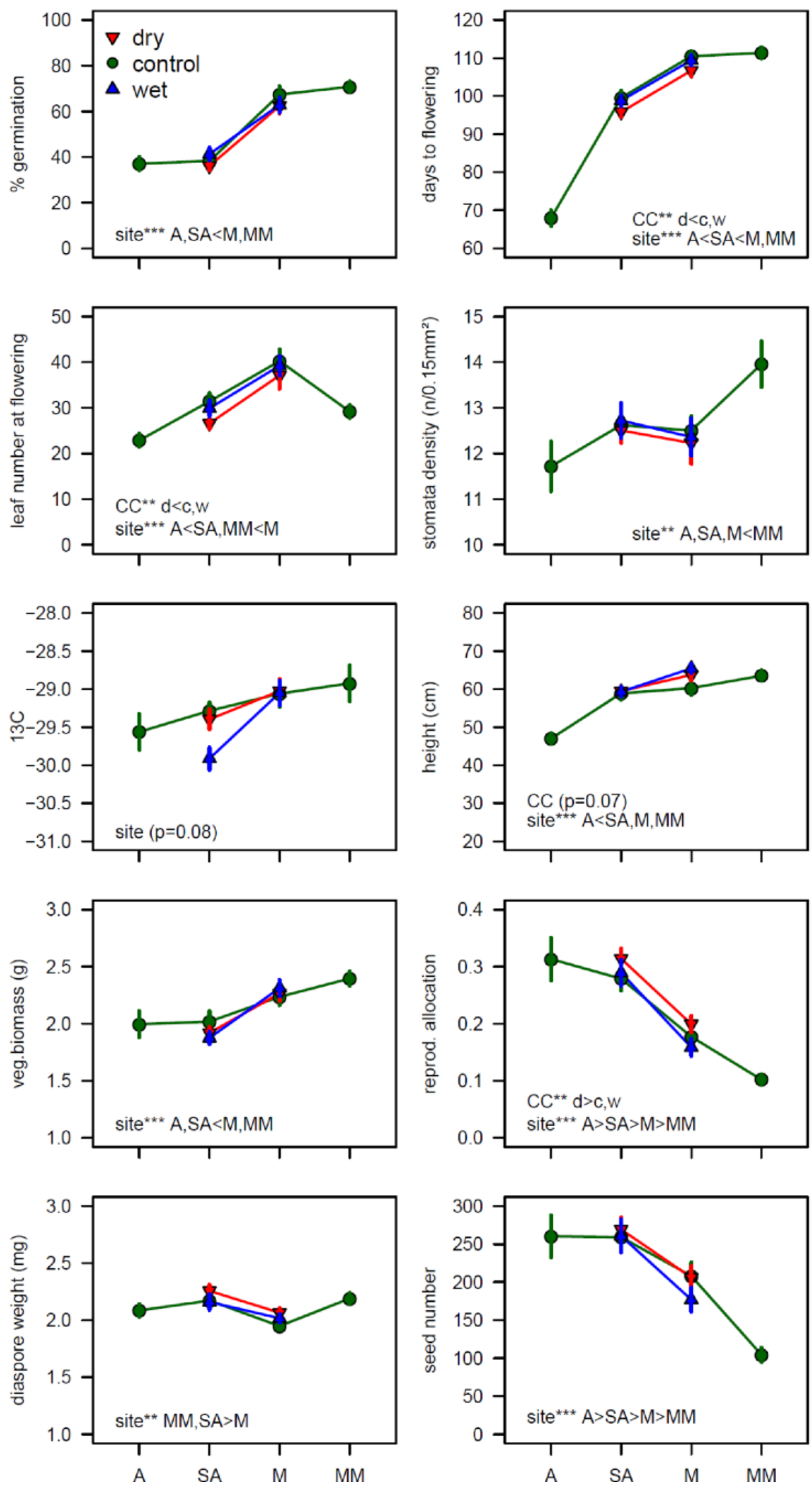
Figure 1 Mean values $( \pm 1 S E)$ for ten traits of genotypes originating from four sites along a natural rainfall gradient (ambient controls, in green), and from additional Climate Change manipulations in the two intermediate sites (CC; with dry/red and wet/blue). Main effects for CC (see Table 1) and site (see Table 2) are added if (marginally) significant $\left({ }^{*} p<0.05,{ }^{* *} p<0.01,{ }^{* * *} p<0.001\right)$.
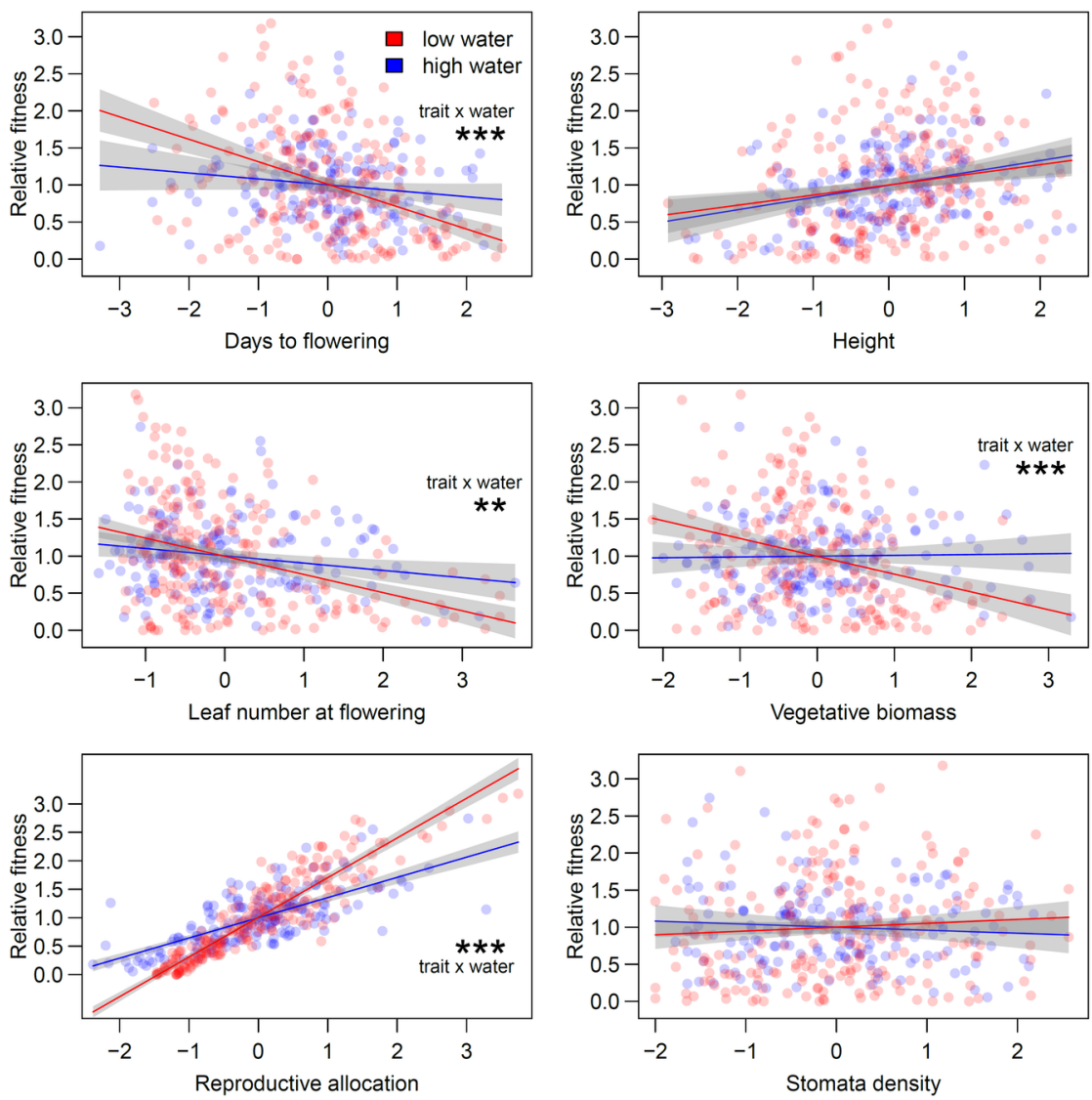

Figure 2 Directional selection in low water levels (red) and high water levels (blue) in the greenhouse. Differential selection between water levels is indicated by their interaction with the tested trait ${ }^{*} p<0.05$, $\left.{ }^{* *} p<0.01,{ }^{* * *} p<0.001\right)$. 

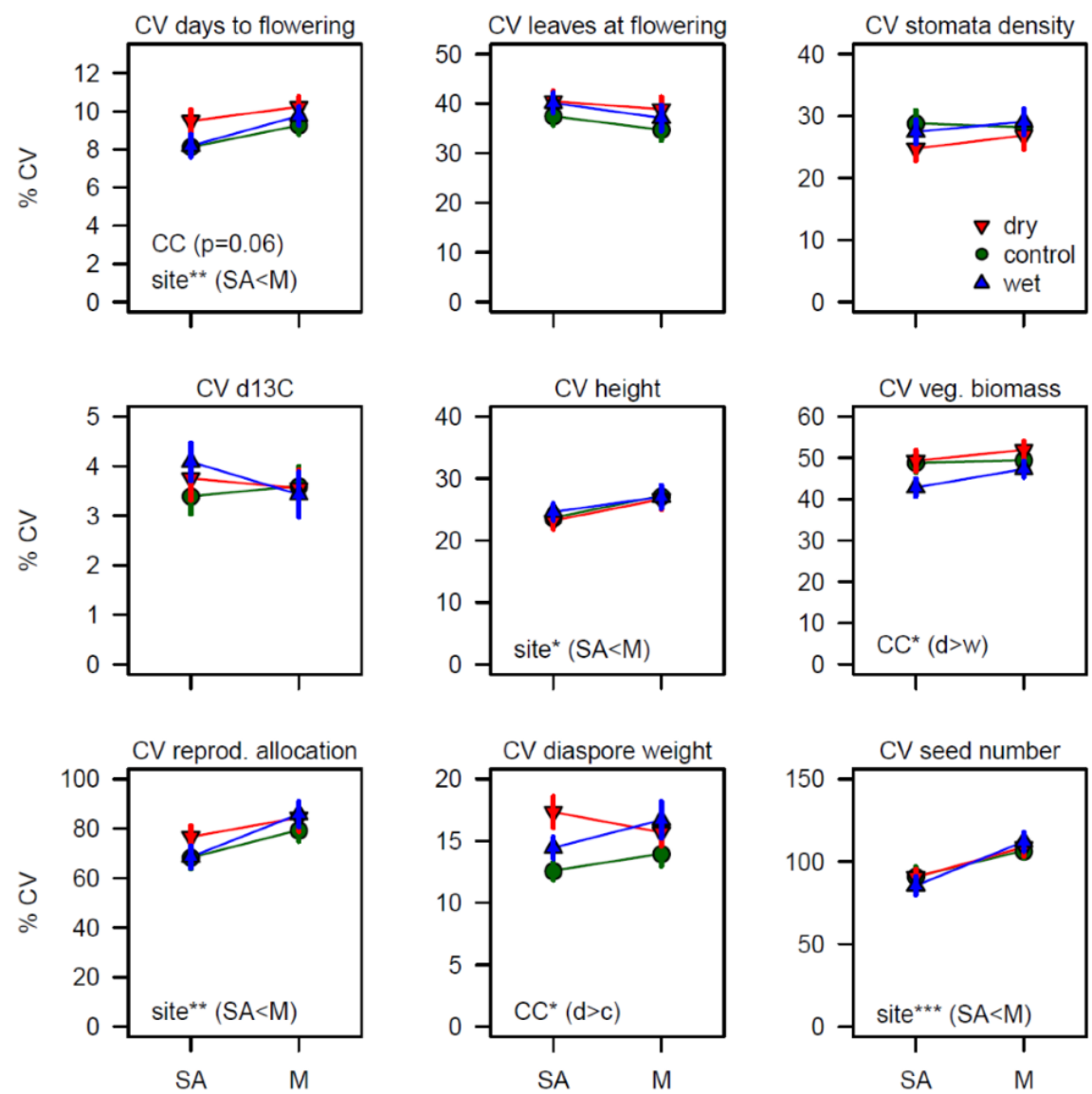

Figure 3 Mean plasticity in nine traits(measured as Coefficient of Variation across five water levels) in plants descending from three Climate Change manipulation treatments $(C C)$ in two sites (semi-arid, Mediterranean). Error bars are $\pm 1 S E$. Note the different $y$-scaling for visualization. Plasticity for germination fraction was not assessed as differential water levels were not yet applied during germination. Main effects for $C C$ and site are added if (marginally) significant $\left({ }^{*} p<0.05,{ }^{* *} p<0.01,{ }^{* * *} p<0.001\right.$; see Table 3 for full results.) 